\title{
O USO DO JARDIM ZOOLÓGICO DO CIGS PARA O ENSINO DE CiÊnCIAS
}

\author{
USING THE CIGS ZOO FOR SCIENCE TEACHING
}

DOI: http://dx.doi.org/10.23926/RPD.2526-2149.2019.v4.n2.p685-696.id524

\section{Francinete Bandeira Carvalho \\ Mestranda em Educação e \\ Ensino de Ciências na \\ Amazônia (PPGEEC/UEA) \\ Bolsista da FAPEAM \\ fran.carvalho15@hotmail.co $\underline{\mathrm{m}}$}

\section{Augusto Fachín Terán Doutor. Professor do Curso de Pedagogia e do Curso de Mestrado em Educação e Ensino de Ciências na Amazônia (PPGEEC/UEA) fachinteran@yahoo.com.br}

\section{Maria Francisca Gomes da Silva} Pedagoga. Especialista em Psicopedagogia maradani2008@hotmail.com
Resumo: Os jardins zoológicos são importantes locais para a educação, pesquisa e conservação da biodiversidade. O nosso objetivo foi sinalizar a possibilidade de se trabalhar o ensino de Ciências num jardim zoológico amazônico. A pesquisa tem uma abordagem qualitativa com enfoque descritivo. Foi realizada durante a disciplina "Educação em Ciências em Espaços Não Formais", ofertada pelo Programa de Pós-Graduação em Educação e Ensino de Ciências na Amazônia. Utilizamos como procedimento a observação direta, com um olhar reflexivo e crítico. Para registro dos dados usamos caderno de campo e câmera fotográfica. O jardim zoológico do CIGS é um ambiente rico em biodiversidade, que possibilita aos alunos um aprendizado por meio de práticas educativas que se aproximam do conhecimento prévio dos alunos. Foi importante para a turma de mestrado vivenciar esta experiência com um olhar de professor pesquisador, de como podemos usar esses espaços nas aulas de Ciências. Refletimos sobre a possibilidade de um ensino que relacione a teoria e a pratica, abrindo caminho para aprendizagens significativas.

Palavras-chave: Espaços não-formais; Ensino de Ciências; Zoológico.

\begin{abstract}
Zoos are important educational tools for teaching, research, and conservation of biodiversity. Our objective was to point out possibilities of working with Science teaching in an Amazon zoo. This is a qualitative research with a descriptive approach. It was carried out during a course entitled "Science Education in non-formal spaces" at Graduate Program in Education and Science Teaching in the Amazon. We used direct observation, with a reflective and critical look. We used field notebook and camera for data recording. The CIGS Zoo is a biodiversity rich environment that enables students to learn through educational practices, in a similar way to students' previous knowledge. It was important for the masters' class to have this experience with a researching professor's view, and how we can use these spaces in science classes. We reflect on the possibility for teaching, relating theory and practice, paving the way for meaningful learning.

Keywords: Non-formal spaces; Science teaching; Zoo.
\end{abstract}




\section{INTRODUÇÃO}

A educação, enquanto um processo de ensino-aprendizagem, é adquirida ao longo da vida dos cidadãos, e o ensino de Ciências tem um papel muito importante, uma vez que contribui na formação de cidadãos críticos e reflexivos, de modo a atuarem no mundo em que vivem (VIEIRA, BIANCONI e DIAS, 2005). É necessário que o cidadão seja capaz de, com base em informações e análises bem fundamentadas, ter participação nas decisões que afetam sua vida, organizando um conjunto de valores, mediado na consciência da importância de sua função no aperfeiçoamento individual e das relações sociais (KRASILCHIK e MARANDINO, 2004). Além desta competência, estes mesmos autores sinalizam que, para ter acesso a esta formação de cidadãos com espírito crítico, outros aspectos a serem observados, também, são importantes: a) ser capaz de expressar seus julgamentos de valor; b) justificar suas decisões referindo-se aos princípios e conceitos em que se basearam; c) diferenciar entre decisões pessoais, de âmbito individual, e decisões coletivas, de âmbito público; d) reconhecer e aceitar direitos, deveres e oportunidades em uma sociedade pluralista; e) ouvir e aceitar diferentes opiniões.

A escola possui papel fundamental na instrumentalização dos indivíduos ante os conhecimentos científicos, por meio do ensino de Ciências, contudo, ela não tem condições de proporcionar todas as informações científicas necessárias para a compreensão do mundo, exigindo que os professores proporcionem este conhecimento fora da escola, ou seja, nos espaços não formais, visto que "a cidadania só pode ser exercida, plenamente, se o cidadão ou cidadã tiver acesso ao conhecimento (e isto não significa apenas informações), assim, cabe aos educadores, então, fazer esta educação científica" (CHASSOT, 2016, p. 82).

Os espaços não formais têm sido usados como ambientes de ensino aprendizagens relevantes, para que os professores consigam maior resultado e profundidade nos conteúdos a serem aprendidos pelos estudantes, rompendo os limites do espaço escolar em busca de uma aprendizagem mais significativa. As aulas nestes espaços tendem a estimular a curiosidade das crianças, uma vez que oferecem a oportunidade de suprir, ao menos em parte, algumas das carências da escola, tais como a falta de laboratórios e de recursos audiovisuais, entre outros, conhecidos por estimular o aprendizado (VIEIRA, BIANCONI e DIAS, 2005). Assim sendo, aprender, nestes ambientes fora da sala de aula, funciona como um motivador para os estudantes, algo novo e cheio de expectativas, visto que "podem contribuir para a formação de valores e atitudes, que possibilitem colocar em prática os conhecimentos construídos nas aulas" (ROCHA e FACHÍN-TERÁN, 2010, p. 53). 
Um Zoológico é um local específico para manter a fauna, a qual pode ser exibida ao público. Nele, há profissionais especializados, como por exemplo, veterinários, biólogos e zootecnistas, que cuidam da alimentação, ambiente, recintos, saúde mental e física dos animais, entre outras atividades. O objetivo deste trabalho é sinalizar a possibilidade de se ensinar e aprender Ciências no jardim zoológico, do Centro de Instrução de Guerra na Selva (CIGS), localizado na cidade de Manaus, no Amazonas, Brasil. No decorrer do trabalho, apresentaremos o que é um jardim zoológico, além de discutirmos algumas das estratégias pedagógicas necessárias para se trabalhar com os estudantes no referido ambiente.

\section{REFERENCIAL TEÓRICO}

\subsection{CONSIDERAÇÕES SOBRE O ENSINO DE CIÊNCIAS}

Salles (2007) argumenta que, no ensino de Ciências, os processos mediadores devem ser capazes de conduzir os alunos a uma aprendizagem significativa. Além disso, visto que quando se trata do Ensino Fundamental, tais processos são de responsabilidade do professor, daí a necessidade deste profissional dominar os conhecimentos específicos desta disciplina. Este autor ressalta, ainda, que a construção do conhecimento humano esteja, diretamente, relacionada com a prática social, a qual leva ao desenvolvimento da sociedade. E é neste contexto que o ensino de Ciências está inserido. A ideia, então, é criar uma cultura, na qual o ensino de Ciências seja prazeroso e significativo para os estudantes, respeitando seu desenvolvimento e conhecimentos prévios.

Nas últimas décadas, muito se tem discutido acerca do ensino de Ciências com grande preocupação em procurar atribuir sentido aos estudos referentes às Ciências da Natureza, uma vez que estas podem contribuir para a imersão do indivíduo numa sociedade permeada por experiências científicas, muitas delas manifestadas nos produtos com intenso aporte tecnológico que rodeiam nossa vida (KRASILCHIK, 2004; SALLES, 2007). Assim, torna-se necessário um novo olhar para o ensino de Ciências, uma vez que, "a educação em Ciências compreende no saber o que é ensinar Ciências e, mais amplamente, no entendimento do que é Ciência" (GONZAGA e FACHÍN-TERÁN, 2011, p. 31).

O Ministério da Educação, através do documento denominado de Currículo Nacional do Ensino Básico - Competências essenciais (BRASIL, 2001), considera que o ensino da Ciência é fundamental, desde a educação básica, de modo a proporcionar aos alunos possibilidades de: a) despertar a curiosidade acerca do mundo natural e criar um sentimento de admiração e interesse pela Ciência; b) adquirir uma compreensão alargada das ideias e das 
estruturas explicativas centrais da Ciência, como, também, dos procedimentos da investigação científica; c) questionar o comportamento humano perante o mundo, bem como o impacto da Ciência e da tecnologia no nosso ambiente e na nossa cultura.

Em virtude do que foi mencionado, percebe-se que parte do ensino de Ciências está voltado para a preservação do ambiente e, assim sendo, o aluno deve perceber-se como integrante deste meio e, igualmente, como um agente transformador, identificando seus elementos e as interações entre eles, contribuindo, significativamente, para sua melhoria e preservação.

O ensino de Ciências requer práticas pedagógicas relevantes, onde os espaços não formais, tais como o jardim zoológico do CIGS, apresentam-se como uma possibilidade de se trabalhar e construir conhecimento.

\subsection{Pesquisas Realizadas no JaRdim zoológico do CIGS}

O CIGS é um espaço não formal com grande potencial pedagógico para ser utilizado pelos professores no processo de ensino-aprendizagem, capaz de promover conhecimento e sentimento de pertença aos estudantes que o visitam.

Entre as pesquisas realizadas nesta instituição, temos a intitulada: "Análise das placas informativas em espaços não formais da cidade de Manaus, Amazonas, Brasil”, que discute a importância das placas, os conteúdos apresentados, as informações nelas contidas, bem como se as mesmas são auto explicativas ou não. Neste estudo foi constatado que nem todos os espaços oferecem conteúdo específico nas placas informativas, e que o professor, ao fazer uso destes espaços, deve realizar uma visita prévia, a fim de avaliar as informações que irá utilizar, verificando a credibilidade das informações científicas contidas nas referidas placas informativas (GHEDIN, GHEDIN e FACHÍN-TERÁN, 2014).

Outro trabalho que merece destaque é o intitulado "Zoológico do CIGS: um espaço não formal para a promoção do ensino de Zoologia no Contexto da Amazônia", que discute a possibilidade da utilização destes espaços como alternativa para o ensino de Zoologia, levando em consideração as potencialidades para a exploração de conteúdos didáticos, tais como animais em extinção, comportamento de animais em cativeiro, flora e fauna amazônica, entre outros, que podem ser estudados, de forma lúdica e prazerosa (ARAÚJO et al., 2011).

O livro intitulado "O potencial pedagógico dos espaços não formais da cidade de Manaus" traz novas perspectivas de ensino no CIGS e mostra que este local, além de possibilitar 
a aprendizagem, realiza também a divulgação do conhecimento científico, proporcionando aos visitantes momentos de lazer e entretenimento (MACIEL e FACHÍN-TÉRAN, 2014).

O livro intitulado "O processo de aprendizagem das crianças por meio da música e elementos sonoros em espaços educativos" discute como se dá o processo de aprendizagem das crianças da pré-escola, usando o tema da fauna Amazônica, a partir das percepções sonoras e o uso da música em espaços educativos, sendo o CIGS um destes espaços. Os autores reportam que o CIGS tem potencialidade para o desenvolvimento de atividades educativas com crianças, e que ao utilizar os sons dos animais, as crianças passam a sentir-se pertencentes àquele lugar (ALENCAR e FACHÍN-TÉRAN, 2015). A interatividade entre as crianças e a fauna em cativeiro é de extrema relevância para que estas percebam quão importante são os seres vivos e o muito que temos que aprender sobre estes organismos.

\subsection{JARDIM ZOOLÓGICO DO CIGS}

O Jardim Zoológico do CIGS está localizado na cidade de Manaus na Av. Cel. Teixeira, 1.320, bairro Ponta Negra. Apresenta vários ambientes para a fauna silvestre, entre os quais podemos citar o espaço dos jabutis; das cobras; das antas; dos grandes felinos; das capivaras; das aves; dos porcos selvagens; a ilha dos macacos (Figura 1); a gaiola do gato maracajá; o ambiente dos jacarés e das cutias; além dos espaços administrativos, como o centro de veterinária, a loja de souvenir, a lanchonete, a sorveteria, a sala de educação ambiental interativa e um aquário. Abriga em média 54 espécies, totalizando 175 espécimes de mamíferos, aves, répteis e quelônios.

É o único zoo, no mundo, administrado por militares (ROCHA e FACHÍN-TERÁN, 2010). Foi criado para possibilitar aos participantes dos cursos de operações na selva do Exército Brasileiro, conhecimentos acerca da fauna da região. Entretanto, logo após sua criação, sofreu algumas alterações e passou a receber visitas do público civil. Desde então, tem se tornado um dos lugares preferidos para os turistas, após passar por uma reforma na sua estrutura física, atendendo aos padrões exigidos pelo IBAMA. 


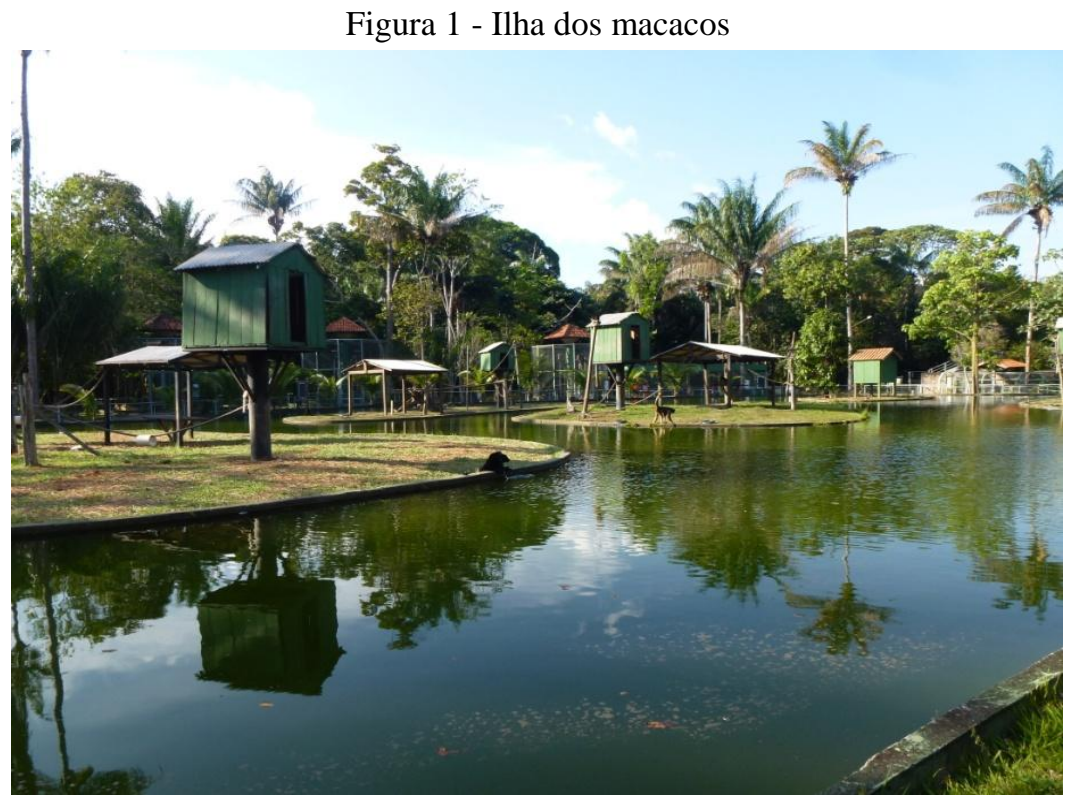

Fonte: Figura selecionada pelos pesquisadores a partir da coleta de dados.

\section{Metodologia}

Este trabalho apoiou-se na pesquisa de campo, que nas ponderações de Cervo e Bervian (2002), é uma investigação empírica, realizando-se pela observação que o pesquisador faz, diretamente, dos fatos ou pela indagação concreta das pessoas envolvidas e interessadas no tema, objeto de estudo. Quanto aos fins, foi descritiva. Para Gil (2002, p. 42), este tipo de pesquisa tem como objetivo fazer “(...) a descrição das características de determinada população ou fenômeno".

A pesquisa foi realizada no Jardim Zoológico do CIGS, durante a disciplina Educação em Ciências em Espaços Não Formais, ofertado pelo Mestrado em Educação e Ensino de Ciências na Amazônia, da Universidade do Estado do Amazonas. Para conhecer o espaço, a infraestrutura e a fauna, percorremos o local, realizando observações e paradas estratégicas, a fim de realizar observações da biodiversidade, nos diversos ambientes. As paradas para a observação foram feitas no aquário, na gaiola das aves, no lago dos jacarés, no ambiente dos felinos e dos jabutis, no lago dos macacos e no serpentário.

Utilizamos como procedimento a observação direta, com um olhar reflexivo e crítico. Para os registros usamos caderno de campo e câmera fotográfica.

\section{Resultados E Discussão}

Chassot (2016) defende a ideia de que é necessário tornar o ensino mais sujo, ou seja, encharcá-lo da realidade, uma vez que segundo ele, há uma preocupação de se fazer um ensino limpo, isto é, um ensino desvinculado da realidade do mundo que se pretende explicar. A forma 
de se fazer isto, seria levar os estudantes para visitar os espaços não formais, tais como parques, zoológicos e Jardins Botânicos, espaços estes que albergam e ofertam conhecimentos sobre a biodiversidade, onde é possível conhecer animais que a maioria deles, só vê em livros, revistas ou na TV, de modo que possam sentir-se responsáveis pelo meio em que vivem e que defendam com sentimento de pertencimento o seu espaço.

Segundo Fachín-Téran e Santos (2013), o ensino e aprendizagem de Ciências em espaços não formais, aproxima a criança da natureza e promove a aquisição de valores e atitudes responsáveis para com o lugar em que ela habita. Para estes autores, o professor precisa assumir uma postura crítica e investigativa, buscando o desenvolvimento de práticas que contemplem tanto o conteúdo, quanto o processo de ensino-aprendizagem, em que os conhecimentos prévios e as experiências das crianças sejam valorizados.

$\mathrm{Na}$ visita realizada, constatamos que a infraestrutura do CIGS é boa, colorida, arborizada, implementada com várias lixeiras para coleta seletiva (Figura 2). Logo de início, já podemos visualizar um tema para estudo: a coleta seletiva de lixo, levando às crianças a aprenderem sobre as diferenças de cada lixo e a importância de separá-los.

Durante o trajeto, percebemos poucos bancos para momentos de descanso e conversa com troca de informações, e também, pouca sombra, tanto para os visitantes, quanto para alguns animais, que se amontoavam para disputar um espaço sem sol, como por exemplo, os jabutis (Chelonoides carbonária) (Figura 3).

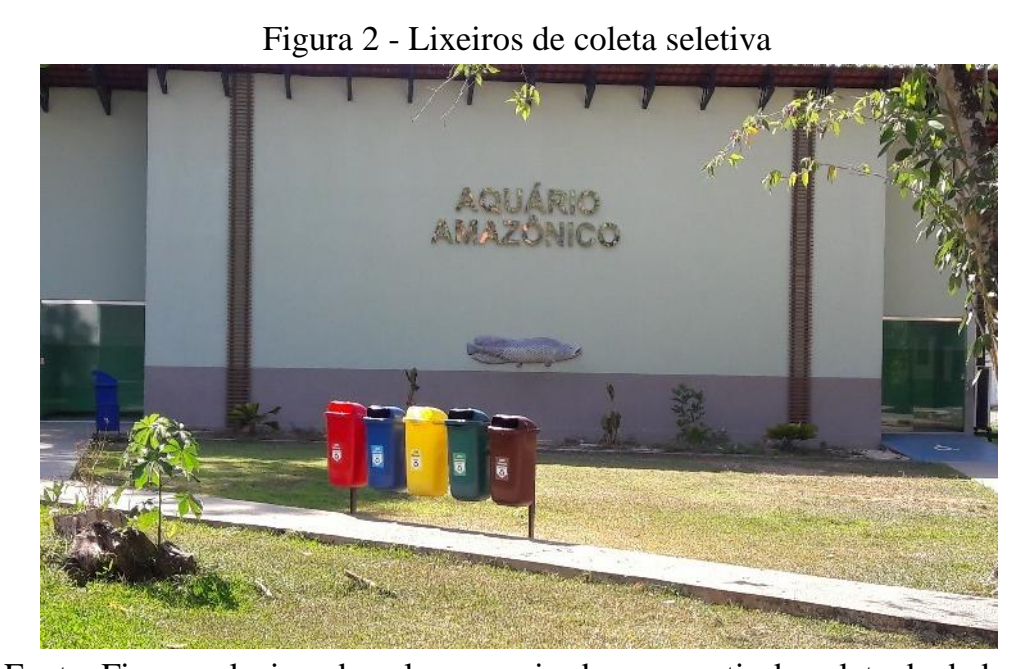

Fonte: Figura selecionada pelos pesquisadores a partir da coleta de dados. 


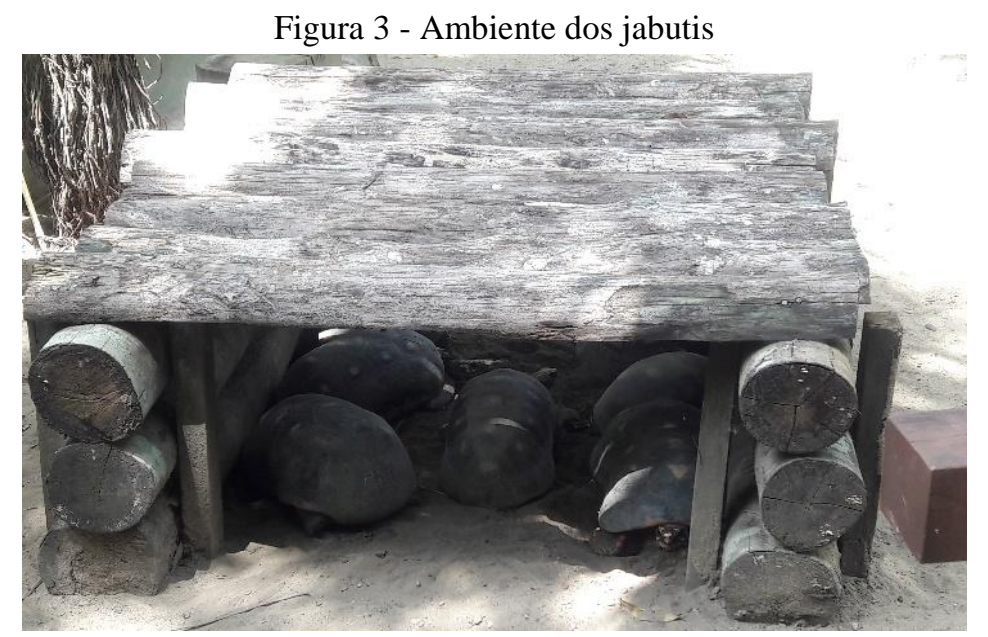

Fonte: Figura selecionada pelos pesquisadores a partir da coleta de dados

Foi registrado que alguns ambientes não apresentam acessibilidade para os cadeirantes, o que dificulta para os mesmos o acesso a todos os locais. Podemos destacar como temática para esta problemática "A importância de garantir a acessibilidade para todos", o que nos levaria a trabalhar outras atividades com os alunos, de modo a sensibilizá-los sobre a importância do acesso ao local para todos os visitantes, independente da dificuldade encontrada para conseguir este objetivo.

Observamos, também, que algumas placas de sinalização e identificação dos animais estavam quebradas e desbotadas devido ao tempo. Contudo, há um número muito bom de placas em bom estado, informando a localização dos animais, da lanchonete, do banheiro e de tudo o que consta no lugar (Figura 4). As placas são explicativas e apresentam-se escritas, também, em outros idiomas, além da língua portuguesa.

Figura 4 - Placas Informativas

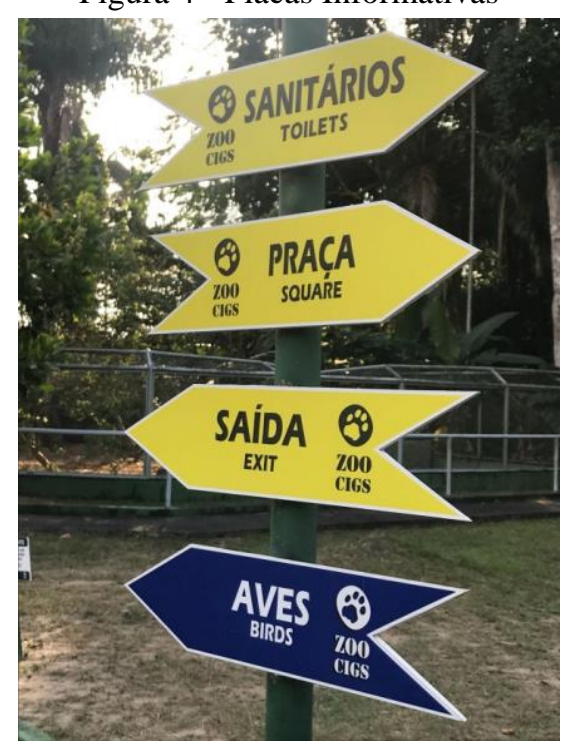

Fonte: Figura selecionada pelos pesquisadores a partir da coleta de dados. 
Embora o espaço e a infraestrutura do CIGS apresentem algumas restrições, tais como "não poder interagir e alimentar os animais", isto não impede a possibilidade de trabalhar o ensino de Ciências, proporcionando aos visitantes, alunos e turistas, os saberes que envolvem o referido lugar.

O jardim zoológico do CIGS alberga uma fauna variada, com animais aquáticos, terrestres e aéreos, cada um com suas características e peculiaridades, que instigam a curiosidade para o aprendizado. O professor como mediador do conhecimento, pode utilizar o CIGS como um espaço de ensino-aprendizagem para construir saberes com seus estudantes, valendo-se, para isto, de diferentes estratégias, tais como a indagação, a observação e a sensibilização, entre outras, de modo a realizar um estudo in loco, com planejamento e organização, antes de efetivar a visita.

Uma estratégia interessante a ser trabalhada seria na forma de roda de conversa, distribuição e explicação de folders com conteúdo sobre a necessidade de se preservar a fauna e a flora amazônica. Depois, encaminhar cada estudante a escolher um animal ou planta, criando um pequeno texto com desenho sobre o mesmo. Kraemer (2010) diz que as atividades lúdicas dão oportunidade para a criança aprender com prazer e que o professor precisa aprender a inserir os conteúdos nestas atividades para facilitar a aprendizagem, alcançando, assim, os seus objetivos. Existe a necessidade de superar a velha prática de alguns professores, de ficarem presos aos livros didáticos descontextualizados do ambiente amazônico (ROCHA e FACHÍNTÉRAN, 2013).

As atividades educativas no CIGS podem induzir diferentes níveis de interatividade entre as crianças e a fauna em cativeiro, como por exemplo, no ouvir e repetir os sons dos animais; no tocar das folhas ou no caminhar no chão para sentir o solo. Como uma atividade complementar pode ser solicitada, ainda, para cada criança anotar os nomes e as características dos animais descritos nas placas (Figura 5) e, em casa, elaborarem um álbum seriado com os referidos animais, visto que as placas contêm várias informações.

Outra atividade para trabalhar com as crianças, seria a observação dos animais, levandoas a pensar o porquê estes se encontram naquele local, instigando-as a entender sobre sua função na natureza e o que pode ser feito, daqui para frente, para protegê-los e, assim, evitar que outras espécies venham a entrar na tão temida lista de animais em perigo de extinção. Depois deste momento, pode-se pedir para que as crianças utilizem massinhas de modelar, no intuito de representar os animais observados e expor suas ideias para o grupo. 


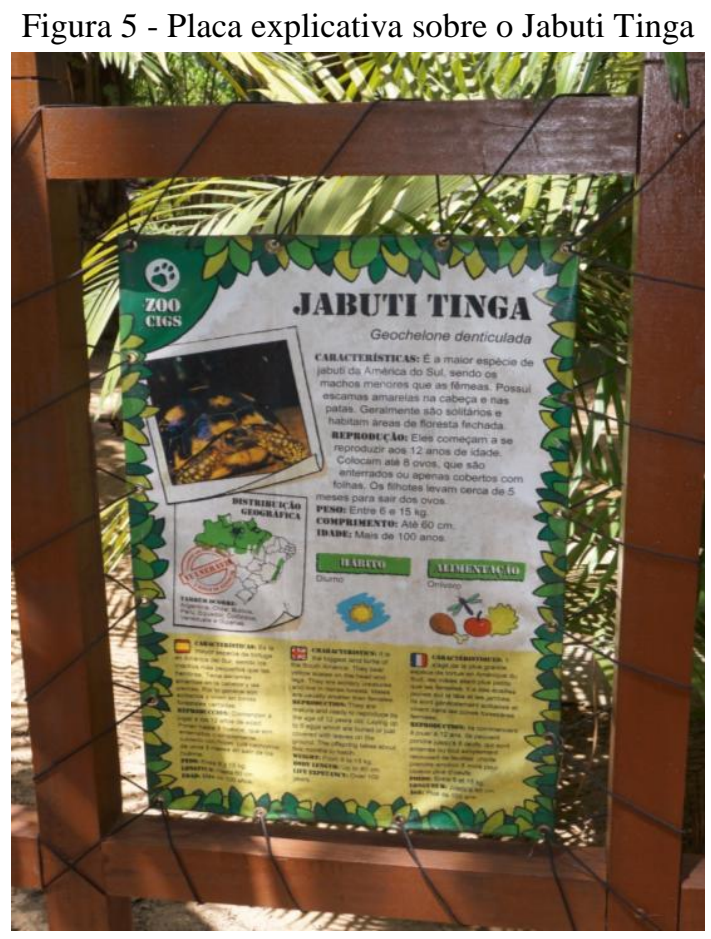

Fonte: Figura selecionada pelos pesquisadores a partir da coleta de dados.

Assim, o ensino de Ciências, nos espaços do jardim zoológico do CIGS, poderá despertar na criança a curiosidade sobre o mundo natural, criando uma admiração sobre o mundo que a cerca, e promovendo ou questionando-a sobre o comportamento humano em relação aos recursos naturais. Visto que o grande propósito de refletir e agir, acerca da educação em Ciências na Educação Infantil, é que esta educação possa ser uma grande oportunidade da criança vir a tornar-se, cada vez mais cedo, um sujeito cientificamente culto (GHEDIN et al., 2013).

\section{CONSIDERAÇõES FinAIS}

Diversas publicações científicas, têm mostrado que os espaços não formais são grandes aliados da escola, visto que a sala de aula já não é mais capaz de suprir, sozinha, todas as necessidades de educar cientificamente. Os alunos precisam mais do que apenas ler livros, responder questionários e/ou decorar perguntas, eles necessitam de um conhecimento sólido e significativo, onde a teoria e a prática andem juntos, proporcionando-lhes um olhar crítico e reflexivo diante dos problemas que se apresentam no seu cotidiano para, assim, serem capazes de atuarem na sociedade onde vivem.

O ensino de Ciências pode despertar no aluno conhecimentos significativos de modo que ele possa atuar no mundo que o cerca. Assim sendo, realizar visitas com esta intencionalidade em espaços não formais, ajuda na construção do conhecimento entre o 
professor e o estudante. Neste sentido, é importante que as visitas aos espaços não formais sejam planejadas com antecedência e que o professor conheça o lugar, previamente, a fim de elaborar um roteiro detalhado e contextualizado, com o passo a passo das paradas estratégicas e das atividades a serem realizadas.

O jardim zoológico do CIGS é um ambiente rico em biodiversidade, que oportuniza aos estudantes uma aprendizagem significativa, mediante estratégias que possibilitem práticas educativas que se aproximam dos saberes prévios dos alunos, proporcionando a eles significado, construção e reconstrução do conhecimento. Constatamos que foi importante para a turma de mestrado vivenciar esta experiência com um olhar de professor pesquisador, de como podemos usar estes espaços nas aulas de Ciências e que o professor precisa fugir um pouco das quatro paredes da sala de aula, bem como dos livros didáticos, mostrando ser esta uma ótima investida na busca por mudanças neste processo de ensino-aprendizagem, vigente, fazendo com que os estudantes despertem o sentimento de pertencimento junto à natureza.

\section{Agradecimentos}

A Danny Neisel Lima Gutarra pela tradução do resumo.

\section{REFERÊNCIAS}

ALENCAR, Raimundo Nonato Brilhante de; FACHÍN-TERÁN, Augusto. O processo de aprendizagem das crianças por meio da música e elementos sonoros em espaços educativos. Manaus: Editora e Gráfica Moderna, 2015. 186p.

ARAÚJO, Joeliza Nunes; SILVA, Cirlande Cabral da; DIAS, Odilene; FACHÍN-TERÁN, Augusto; GIL, Antonio Xavier. Zoológico do CIGS: um espaço não-formal para a promoção do ensino de zoologia no contexto da Amazônia. Trabalho de comunicação oral apresentado no I Simpósio Internacional de Educação em Ciências na Amazônia - I SECAM. 2011. Disponível em: https://ensinodeciencia.webnode.com.br/. Acesso em: 20 ago. 2019.

BRASIL. Ministério da Educação. Currículo Nacional do Ensino Básico - Competências essenciais. Ciências Físicas e Naturais, 2001.

CERVO, Amado Luiz; BERVIAN, Pedro Alcino. Metodologia científica. 4 ed. São Paulo: Makron Books, 2002.

CHASSOT, Attico. Alfabetização científica: questões e desafios para a educação. 7 ed. Ijuí: Unijuí, 2016.

FACHÍN-TÉRAN, Augusto; SANTOS, Saulo Cézar Seiffert. Novas perspectivas de Ensino de ciências em espaços não formais amazônicos. Manaus/AM: UEA Edições, 2013.

GHEDIN, Leila Marcia; MARQUES, Fábio Francisco de Freitas; FACHÍN-TERÁN, Augusto; GHEDIN, Iliane Margarete. A educação científica na educação infantil. Areté. 
Revista Amazônica de Ensino de Ciências, v.6, n.10, 2013, p. 42-52. Disponível em: http://periodicos.uea.edu.br/index.php/arete/article/view/59. Acesso em: 10 fev. 2019.

GHEDIN, Leila Marcia; GHEDIN, Iliane Margarete; FACHÍN-TERÁN, Augusto. Análise das placas informativas em espaços não formais da cidade de Manaus, Amazonas, Brasil. $4^{\circ}$ Encontro Internacional de Ensino e Pesquisa em Ciências na Amazônia. 2014. Disponível em: https://ensinodeciencia.webnode.com.br/. Acesso em: 20 ago. 2019.

GIL, Antônio Carlos. Como elaborar projetos de pesquisa. 4 ed. São Paulo: Atlas, 2002.

GONZAGA, Leila Teixeira; FACHÍN-TERÁN, Augusto. Espaços não-formais: contribuições para educação científica em educação infantil. In: BARBOSA, Ierecê et al. (orgs.). Avanços e desafios em processos de educação em Ciências da Amazônia. Pp. 30-46. Manaus: UEA/Escola Normal Superior/PPGE-ECA, 2011.

KRAEMER, Maria Luiza. Formação de Professores: Aprendendo com criatividade. Campinas, SP: Autores Associados, 2010.

KRASILCHIK, Myriam; MARANDINO, Martha. Ensino de Ciências e Cidadania. São Paulo: Moderna, 2004.

MACIEL, Hiléia; FACHÍN-TERÁN, Augusto. O potencial pedagógico dos espaços não formais da cidade de Manaus. Curitiba, PR: CRV, 2014. 128p.

ROCHA, João Marinho da; FACHÍN-TÉRAN, Augusto. O projeto manejo de quelônios amazônicos "pé-de-pincha" e sua contribuição na educação científica em duas comunidades ribeirinhas do assentamento agrícola "Vila Amazônia", Parintins-AM. In: Novas perspectivas de Ensino de ciências em espaços não formais amazônicos. Manaus/AM: UEA Edições, 2013.

ROCHA, Sônia Claúdia Barroso da; FACHÍN-TERÁN, Augusto. O uso de espaços não formais como estratégia para o ensino de ciências. Manaus: UEA/Escola Normal Superior/PPGEECA, 2010.

SALLES, Gilsani Dalzoto. Metodologia do ensino de ciências biológicas e da natureza. Curitiba: Ibpex, 2007.

VIEIRA, Valéria; BIANCONI, Maria Lucia; DIAS, Monique. Espaços não-formais de ensino e o currículo de ciências. Ciência e Currículo, v.57, n.7, 2005, p. 21-23. Disponível em: http://cienciaecultura.bvs.br/pdf/cic/v57n4/a14v57n4.pdf. Acesso em: 15 fev. 2019.

Recebido em: 14 de setembro de 2019.

Aprovado em: 19 de dezembro de 2019. 